\section{Airborne pollutants and lacunar stroke: a case cross-over analysis on stroke unit admissions}

\author{
Francesco Corea, ${ }^{1}$ Giorgio Silvestrelli, ${ }^{2}$ \\ Andrea Baccarelli, 3 Alessandra Giua, 4 \\ Paolo Previdi,2 Giorgio Siliprandi, 5 \\ Nicola Murgia6 \\ 1Brain Injury Unit, Ospedale San Giovanni \\ Battista, Foligno; 2Stroke Unit, Division \\ of Neurology, Carlo Poma Hospital, \\ Mantua; ${ }^{3}$ Department of Environmental \\ and Occupational Health, IRCCS \\ Maggiore Policlinico Hospital, Mangiagalli \\ and Regina Elena Foundation and \\ University of Milano; ${ }^{4}$ Clinica \\ Neurologica, Università di Sassari; \\ ${ }^{5}$ Regional Environmental Protection \\ Agency, Mantua; ${ }^{6}$ Section of \\ Occupational Medicine, Respiratory \\ Diseases and Toxicology, University \\ of Perugia, Italy
}

\section{Abstract}

Particulate air pollution is known to be associated with cardiovascular disease. The relation of particulate air pollution with cerebrovascular disease (CVD) has not been extensively studied, particularly in relation to different subtypes of stroke. A time-series study was conducted to evaluate the association between daily air pollution and acute stroke unit hospitalizations in Mantua, Italy. We analyzed 781 CVD consecutive patients living in Mantua county admitted between 200608. Data on stroke types, demographic variables, risk factors were available from the Lombardia Stroke Registry. Daily mean value of particulate matter with a diameter $<10 \mu \mathrm{m}$ $\left(\mathrm{PM}_{10}\right)$, carbon monoxide, nitric oxide, nitrogen dioxide, sulphur dioxide, benzene and ozone were used in the analysis. The association between CVD, ischemic strokes subtypes and pollutants was investigated with a casecrossover design, using conditional logistic regression analysis, adjusting for temperature, humidity, barometric pressure and holidays. Among the 781 subjects admitted 75.7\% had ischemic stroke, $11.7 \%$ haemorrhagic stroke $12.6 \%$ transient ischemic attack. In men admission for stroke was associated with $\mathrm{PM}_{10}$ [odds ratio (OR) 1.01, 95\%; confidence interval (CI) $1.00-1.02 ; \mathrm{P}<0.05]$. According to the clinical classification, lacunar anterior circulation syndrome stroke type was related to $\mathrm{PM}_{10}$ level registered on the day of admission for both genders (OR: 1.01, 95\%; CI: 1.00-1.02;
$\mathrm{P}<0.05)$ while for total anterior circulation syndrome stroke only in men (OR: 1.04, 95\%; CI 1.01-1.07; $\mathrm{P}<0.05)$.

In conclusion, our study confirms that air pollution peaks may contribute to increase the risk of hospitalization for stroke and particulate matter seems to be a significant risk factor, especially for lacunar stroke.

\section{Introduction}

Many studies conducted in several parts of the world documented consistent effects of air pollution on public health. ${ }^{1-4}$ Air pollution is mostly generated by human activities such as industrial sources, fires and crustal material, but it also originates from natural events, like, for instance, the volcanic ashes recently observed in Ecuador and Iceland ${ }^{5}$ Specifically, exposure to particulate air pollution has been linked with increased mortality and morbidity from cardiovascular and respiratory disease mediated by the induction of oxidative stress by these particles triggering coagulation and thrombosis. ${ }^{6}$ These effects have been explained by release of soluble mediators by the lungs, inducing systemic events including inflammation, blood coagulation, and atherosclerosis, by the direct translocation of ultra fine particles into the systemic circulation, or by the alteration in autonomic cardiac control ${ }^{6-9}$

More recently, particulate air pollution was also associated with cerebrovascular diseases (CVD). $., 10,11$

The negative effect of airborne pollution on the population needs to be further clarified in order to reach agreement on the more appropriate safety thresholds for the public health.

The association between CVD and air pollution has been already studied, but just few studies have analysed the influence of environmental pollutants and different types of stroke. 12 The objective of our study is to assess the influence of airborne pollutants on the hospitalization for acute CVD, by their types, according to Oxfordshire Community Stroke Project (OCSP) and Trial of Org Acute Stroke Trial (TOAST) classifications. 13,14

\section{Materials and Methods}

\section{Study population}

Of the 1680 consecutive patients admitted to Mantua (Italy) Stroke Unit from January 1st, 2006, to December 31 st, 2008, we analysed 781 (46.5\%) cases living in the urban area within $10 \mathrm{~km}$ from one of the urban air pollution stations. The limit of $10 \mathrm{~km}$ is considered an appropriate distance from the recording site for quantifying the exposure of the population
Correspondence: Francesco Corea, Dipartimento di Riabilitazione, Unità Gravi Cerebrolesioni, Nuovo Ospedale San Giovanni Battista, via Massimo Arcamone, 06034 Foligno, Italy.

Tel. +39.0742.3397970 - Fax: +3907423397962. E-mail: f.corea@asl3.umbria.it

Key words: lacunar stroke, air pollution, stroke registry.

Contributions: FC, GSilv, design of the study and draft manuscript; NM, statistical analysis and helped to design and draft the manuscript; $\mathrm{AB}$, AG, GSili, PP, conceived of the study, design and coordination and helped to draft the manuscript.

Conflict of interests: FC: received modest travel grants for conferences from the following pharmaceuticals industries: Biogen Idec, Merck Serono and Chiesi. The authors declare that they have no other competing and financial interests or potential conflicts of interest.

Acknowledgements: the authors would thank Chiara Crestanini, Elisa Messora and Alessandra Cani for their contribution to collecting data and following patients at Stroke Unit of Carlo Poma Hospital, Mantua, Italy; Dr. Barbara Belloni for reviewing the manuscript draft.

Received for publication: 22 January 2012.

Revision received: 15 May 2012.

Accepted for publication: 26 June 2012.

This work is licensed under a Creative Commons Attribution NonCommercial 3.0 License (CC BYNC 3.0).

(C) Copyright F. Corea et al., 2012

Licensee PAGEPress, Italy

Neurology International 2012; 4:e11

doi:10.4081/ni.2012.e11

to outdoor pollution. Preliminary data of the study are presented elsewhere. ${ }^{15}$

We analyzed all consecutive patients hospitalized in Mantua Stroke Unit for a Transient Ischemic Attack (TIA) or stroke over three years (from January the 1st , 2006 to December $31^{\text {st }}, 2008$ ) and enrolled in the Lombardia Stroke Unit Network (SUN) registry. All patients, or relatives, gave written informed consent to the SUN epidemiological survey, that was previously approved by the local health care authorities (Regione Lombardia) as a permanent diseases registry. 16,17

The hospital registry recorded all strokes and TIA among patients admitted in the Stroke Unit of Carlo Poma Hospital in Mantua, which is the only tertiary centre of the county for stroke admission. The arrival time from stroke onset in the Mantua Stroke Unit, according to the periodical monitoring, ranges between 2 to 25 hours. The majority of stroke patients 
(70\%) in study period was admitted within 16 hours from onset.

The ischaemic or haemorrhagic subtype was identified by computed tomography (CT) scan or by magnetic resonance imaging (MRI) in more than $98 \%$ of the cases ( $87 \%$ CT scan, $13 \%$ DWI). We also collected data on risk factors for stroke such as gender, age, hypertension), ischaemic heart disease [history of angina pectoris or myocardial infarction or ischaemic features on electrocardiogram (ECG)], cardiac arrhythmia (history of atrial fibrillation, by electrocardiogram or diagnosed on ECG or Holter recording), diabetes mellitus (fasting plasma glucose level $>7.8 \mathrm{mmol} / \mathrm{L}$ or patients who had been treated with insulin or oral hypoglycaemic drugs), dyslipidemia (total cholesterol level $>6.0 \mathrm{mmol} / \mathrm{L}$ or treatment with lipid-lowering drugs) and smoking history (ex-smoker and current smoker). Two-dimensional echocardiography was performed to detect possible cardioembolic source. Carotid and vertebral ultrasonography were routinely performed. Diagnosis of the subtypes of stroke was always performed on clinical and cerebral imaging: ischaemic stroke from atheroma of large arteries; ischaemic stroke from small vessel disease, so called lacunar infarct; ischaemic stroke from cardiac embolism; primary cerebral haemorrhagic stroke; subarachnoid haemorrhagic stroke. All available data regarding the patients risk factors profile and hospital diagnostic procedures (e.g. vascular imaging, laboratory results etc.) were taken into account. When it was difficult to differentiate ischaemic stroke from atheroma of large arteries, lacunar infarct and cardiac embolism, consensus meetings were performed to classify the difficult cases in one of the three groups. A transient ischaemic attack was diagnosed when clinical symptoms disappeared within 24 hours without any infarct lesion on imaging.

Stroke subtypes were defined at discharge, according to the TOAST and OCSP criteria. $13,14,18,19$

\section{Air pollution and meteorology data}

The county of Mantua, which includes about 70 municipalities, is located in Lombardy, Northern Italy and has about 400,000 inhabitants with a population density of 172.6 peo$\mathrm{ple} / \mathrm{Km}^{2}$. The city of Mantua has 47,649 inhabitants (December 2007) in an area of $63.9 \mathrm{~km}^{2}$ and a population density of 745 people per $\mathrm{Km}^{2}{ }^{20}$ The major air pollution sources in the area originate from combustion (i.e. automobile exhausts, heating systems) and other crustal erosion or mechanical processes (i.e. wind, fire, industrial activity). ${ }^{21}$

Mantua has a 4-seasons climate and an annual temperature range of $2.1^{\circ} \mathrm{C}$ to $33.2^{\circ} \mathrm{C}$. Data on 24-hours average temperature and relative humidity were obtained from the National Meteorological Office.
Air pollution data were provided by the Regional Environmental Protection Agency ARPA - of Lombardy.

For all air pollutants, we considered the daily average values. In particular the data collected for the following meteorological parameters and the following environmental pollutants concern: temperature, humidity, barometric pressure, particles of diameter $<10$ micron $\left(\mathrm{PM}_{10}\right)$, carbon monoxide (CO), nitrogen dioxide $\left(\mathrm{NO}_{2}\right)$, sulfur dioxide $\left(\mathrm{SO}_{2}\right)$, benzene, nitric oxide (NO) and ozone $\left(\mathrm{O}_{3}\right)$.

Exposure measurements during the study period were taken from 7 monitoring sites (1. Gramsci; 2. S. Agnese; 3. Tridolino; 4. Ariosto; 5. Lunetta; 6. Porto Mantovano; 7. Bosco Fontana), which provide hourly measurements of total suspended particles (TSP; by x-ray absorption) and gaseous pollutants: sulfur dioxide ( $\mathrm{SO}_{2}$; by ultraviolet fluorescence), nitrogen dioxide $\left(\mathrm{NO}_{2}\right.$; by chemiluminescence), ozone $\left(\mathrm{O}_{3}\right.$; by ultraviolet photometry), and carbon monoxide ( $\mathrm{CO}$; by non-dispersive infrared photometry).

We calculated the hourly mean value of each pollutant collected from the 7 monitoring stations and then computed their 24-hours average values. For ozone, a daytime 8-hours average interval instead of a 24 -hours interval was used.

\section{Data analyses}

The case-crossover design was used to study the association between air pollution and hospital admission for CVD. ${ }^{22}$ According to this design, a variant of the case-control design, each subject serves as his/her own control; controls were selected to focus on times (e.g. days) in which the event did not occur. Thus, all individual characteristics not varying during the given time are adjusted to fit the design. For this study, a bidirectional symmetric case-crossover design was used, selecting days $1,3,5,7$ before and after the event (admission for stroke) as control days.

To evaluate the effect of air pollution a multi-pollutant conditional logistic regression model was performed, considering the effect of all pollutants, controlling for barometric pressure, average temperature, weekdays, holidays, the day after a holiday and dividing the cases according to gender and stroke subtype.

The statistical analyses were performed by the statistical software package SPSS Statistics 18.0 (IBM SPSS, Chicago, IL, USA).

\section{Results}

Demographic and baseline characteristics of the 781 cases are displayed on Table 1. The leading risk factor for stroke was hypertension followed by smoking history and diabetes. The more common index event was an ischemic stroke due to small artery occlusion.

The annual distribution of stroke unit admissions followed the typical seasonal variation, with a peak of ischemic event in fall-winter, and is described elsewhere. ${ }^{23}$

\section{Stroke Unit admission}

The estimated effects of air pollutants stratified by gender, adjusted for temperature, humidity holidays are displayed in Table 2 . Higher level of $\mathrm{PM}_{10}$ were associated with increased risk of hospital admission for any cerebrovascular event [odds ratio (OR): 1.01, 95\%; confidence interval (CI): 1.00-1.02; $\mathrm{P}<0.05$ ]; men exposed to higher concentration of $\mathrm{PM}_{10}$ have a slight, not significant, higher risk of ischemic strokes (OR: 1.01, 95\%; CI: $1.00-1.02 ; \mathrm{P}=0.06$ ), but not for haemorrhages and TIAs. In holidays, subjects were less prone to be hospitalized (OR 0.71; 95\% CI: 0.56-0.91, $\mathrm{P}<0.05)$ for stroke, while they were more frequently admitted for ischemic stroke the day after an holiday (OR 1.30 , 95\% CI: 1.04-1.63, $\mathrm{P}<0.05)$.

Table 1. Demographic, baseline, etiological and clinical characteristics of 781 cases.

\begin{tabular}{lc}
\hline N. & 781 \\
Age (mean \pm SD) & $71.2 \pm 10.5$ \\
\hline Gender (male) & $366(46.8 \%)$ \\
Risk factors & \\
Atrial fibrillation & $136(17.4 \%)$ \\
Previous TIA/stroke & $170(21.8 \%)$ \\
Hypertension & $587(75.2 \%)$ \\
Ischemic heart disease & $95(12.2 \%)$ \\
Diabetes mellitus & $176(22.5 \%)$ \\
Hyperlipidemia & $250(32 \%)$ \\
Ever smoking & $303(38.8 \%)$ \\
Family history VD & $196(25.1 \%)$ \\
Obesity & $52(6.6 \%)$ \\
Alcohol abuse & $12(1.5 \%)$ \\
\hline Type of stroke & \\
TIA & $108(13.8 \%)$ \\
Ischemic stroke & $567(72.6 \%)$ \\
Haemorrhagic stroke & $106(13.6 \%)$ \\
TOAST classification & \\
LVD & $55(9.7 \%)$ \\
CE & $144(25.4 \%)$ \\
SVD & $218(38.5 \%)$ \\
Unknown & $126(22.2 \%)$ \\
Other & $24(4.2 \%)$ \\
\hline OCSP classification & \\
TACI & $57(10.1 \%)$ \\
PACI & $199(35.0 \%)$ \\
LACI & $239(42.2 \%)$ \\
\hline TIA, transient ischemic attack; SVD, small vessel disease; LVD, large \\
vessel disease; CE, cardioembolic disease; UNK, unknown cause; \\
OTHER, other determined cause; PACI, partial anterior circulation \\
syndrome; TACI, total anterior circulation syndrome; LACI, lacunar \\
anterior circulation syndrome; POCI, posterior occipital circulation \\
syndrome. & \\
&
\end{tabular}




\section{Ischemic stroke subtypes}

The impact of air pollution on ischemic strokes subtypes according to the TOAST and OCPS classification is presented in Tables 3 and 4 . In men, total anterior circulation syndrome (TACI) stroke subtype was associated to higher level of $\mathrm{PM}_{10}$ on the day of the hospital admission (OR 1.04, 95\% CI: 1.01-1.07, $\mathrm{P}<0.05)$. Levels of $\mathrm{PM}_{10}$ was also associated in the general population to lacunar anterior circulation syndrome (LACI) stroke subtype (OR 1.01, 95\% CI: 1.00-1.02, P<0.05). Subtypes of lacunar syndromes included pure motor stroke in $20 \%$ of patients, sensorimotor stroke in $33 \%$, pure sensory stroke in 20\% atypical lacunar syndrome in $15 \%$, ataxic hemiparesis in $6 \%$ and dysarthria-clumsy hand in $6 \%$.

According to the TOAST classification, $\mathrm{PM}_{10}$ influenced, though not significantly, small artery occlusions stroke subtype admission (OR 1.01, 95\% CI: 0.99-1.01) and large artery disease stroke subtype admission (OR 1.02, 95\% CI: 0.99-1.04).

\section{Discussion}

\section{Environmental pollution and stroke subtypes}

Our study suggests that environmental pollution by particulate matter could have a role as a risk factor in cerebrovascular diseases, even if our results deserve some caution in interpretation. To the best of our knowledge no earlier study has used both the TOAST and OCSP classification criteria to analyze the effect of airborne pollutants in stroke unit hospitalization. $12,24,25$

The largest studies conducted so far have been based on social security files (e.g. Medicare) without a detailed clinical assessment; furthermore, several of those based on more detailed clinical information available did not use any detailed brain imaging support.12,24,25 The main benefits of our single centre design are that no patient was lost to follow-up in the consecutive series of subjects admitted in the stroke unit, standardized procedures were used for stroke ascertainment and classification, and all of the cases were selected for the study based on their usual living area.

We found a high prevalence of lacunar syndromes in the study population and a predictive value for stroke unit admission of $\mathrm{PM}_{10}$ in this subtype of events. This finding can be related to the high prevalence of hypertension in the study population and an excess of lacunar strokes in hypertensive subjects is a well known issue in literature.12,26-28 As a matter of fact, $\mathrm{PM}_{10}$ was recently associated to an increase of blood pressure in men.29,30 The influence of $\mathrm{PM}_{10}$ levels was clear in some subtypes of ischemic events and mostly in the male gender, this phenomenon was previously demonstrated in other clinical studies and the possible mechanism taken into consideration is a larger involvement of microvessels angiopathy in these subjects, leading to higher risks of lacunar infarction as well as renal glomerular impairment. 31,32

\section{Validity issues}

Our study, differently from other experiences, is not likely to be biased by the inclusion of events in patients not monitored by the air pollution stations taken into account.1,24 The resident population in the province of Mantua is characterized by a marked permanence unlike residents in other provinces of Lombardy, which are often commuters to the urban area of Milan. Another

Table 2. Risk of admission for any cerebrovascular event or ischemic stroke and influence of air pollution, by gender.

\begin{tabular}{|c|c|c|c|c|}
\hline & \multicolumn{2}{|c|}{ Any cerebrovascular event } & \multicolumn{2}{|c|}{ Ischemic stroke } \\
\hline & $\begin{array}{c}\text { Men } \\
\text { ORa }(95 \% \mathrm{CI})\end{array}$ & $\begin{array}{c}\text { Women } \\
\text { ORa }(95 \% \text { CI) }\end{array}$ & $\begin{array}{c}\text { Men } \\
\text { ORa }(95 \% \text { CI) }\end{array}$ & $\begin{array}{c}\text { Women } \\
\text { ORa }(95 \% \mathrm{CI})\end{array}$ \\
\hline $\mathrm{PM}_{10}$ & $1.01(1.00-1.02)^{*}$ & $1.00(0.99-1.01)$ & $1.01(1.00-1.02)^{\circ}$ & $1.00(0.99-1.01)$ \\
\hline $\mathrm{SO}_{2}$ & $0.99(0.95-1.04)$ & $0.99(0.96-1.03)$ & $0.99(0.94-1.04)$ & $0.97(0.92-1.02)$ \\
\hline $\mathrm{NO}_{2}$ & $0.99(0.97-1.01)$ & $0.99(0.97-1.02)$ & $1.00(0.97-1.02)$ & $0.99(0.97-1.02)$ \\
\hline NO & $1.00(0.99-1.01)$ & $1.00(0.99-1.02)$ & $1.00(0.98-1.01)$ & $1.01(0.99-1.02)$ \\
\hline $\mathrm{O}_{3}$ & $0.99(0.98-1.01)$ & $1.01(0.991 .02)$ & $0.99(0.98-1.00)$ & $1.00(0.99-1.02)$ \\
\hline $\mathrm{CO}$ & $1.07(0.54-2.13)$ & $1.34(0.66-2.74)$ & $1.01(0.45-2.26)$ & $1.11(0.47-2.63)$ \\
\hline Benzene & $0.95(0.78-1.15)$ & $1.13(0.94-1.36)$ & $0.94(0.76-1.16)$ & $1.16(0.93-1.44)$ \\
\hline
\end{tabular}

Adjusted for temperature, humidity, barometric pressure, day of the week, holidays, day after holidays. $\mathrm{PM}_{10}$, particles of diameter $<10$ micron; $\mathrm{SO}_{2}$ sulfur dioxide; $\mathrm{NO}_{2}$ nitrogen dioxide; $\mathrm{NO}$ nitric oxide; $\mathrm{O}_{3}$ ozone; $\mathrm{CO}$ carbon monoxide. * ${ }^{*}(\mathrm{OR} 1.008 ; 95 \% \mathrm{CI} 1.000-1.016$ with $\mathrm{P}<0.05)$. ${ }^{\circ}(\mathrm{OR}$ $1.008 ; 95 \%$ CI $1.000-1.017$ with $\mathrm{P}=0.06$ ).

Table 3. Risk of admission for stroke subtypes (TOAST classification) and influence of air pollution.

\begin{tabular}{lccc} 
& IVD & CE & SVD \\
& $0 \operatorname{Ra}(95 \% \mathrm{CI})$ & $0 \operatorname{Ra}(95 \% \mathrm{CI})$ & $0 \operatorname{Ra}(95 \% \mathrm{CI})$ \\
$\mathrm{PM}_{10}$ & $1.02(1.00-1.04)$ & $0.99(0.98-1.01)$ & $1.01(1.00-1.02)$ \\
$\mathrm{SO}_{2}$ & $1.00(0.88-1.14)$ & $0.97(0.90-1.04)$ & $0.97(0.91-1.02)$ \\
\hline $\mathrm{NO}_{2}$ & $1.00(0.94-1.06)$ & $1.00(0.97-1.04)$ & $0.98(0.95-1.01)$ \\
$\mathrm{NO}$ & $1.01(0.97-1.05)$ & $1.01(0.99-1.03)$ & $1.00(0.99-1.02)$ \\
\hline $\mathrm{O}_{3}$ & $1.02(0.99-1.06)$ & $0.99(0.97-1.01)$ & $1.00(0.98-1.01)$ \\
$\mathrm{CO}$ & $0.14(0.01-1.78)$ & $2.06(0.65-6.52)$ & $1.79(0.71-4.54)$ \\
\hline Benzene & $1.51(0.77-2.96)$ & $0.98(0.71-1.35)$ & $0.92(0.74-1.14)$ \\
\hline
\end{tabular}

Adjusted for temperature, humidity, barometric pressure, day of the week, holidays, day after holidays. $\mathrm{PM}_{10}$, particles of diameter $<10$ micron; $\mathrm{SO}_{2}$ sulfur dioxide; $\mathrm{NO}_{2}$ nitrogen dioxide; $\mathrm{NO}$ nitric oxide; $\mathrm{O}_{3}$ ozone; $\mathrm{CO}$ carbon monoxide. $\mathrm{SVD}$, small vessel disease; $\mathrm{LVD}$, large vessel disease; $\mathrm{CE}$, cardioembolic disease.

Table 4. Risk of admission for stroke subtypes (OCPS classification) and influence of air pollution.

\begin{tabular}{lcccc} 
& PACI & TACI & POCI & LACI \\
& ORa $(95 \% \mathrm{CI})$ & $0 \mathrm{Ra}(95 \% \mathrm{CI})$ & $0 \mathrm{Ra}(95 \% \mathrm{CI})$ & $0 \mathrm{Ra}(95 \% \mathrm{CI})$ \\
$\mathrm{PM}_{10}$ & $1.00(0.99-1.01)$ & $1.00(0.97-1.03)$ & $1.00(0.98-1.02)$ & $1.01(1.00-1.02)^{*}$ \\
$\mathrm{SO}_{2}$ & $0.98(0.93-1.04)$ & $0.87(0.76-0.99)$ & $1.00(0.89-1.11)$ & $1.01(0.95-1.07)$ \\
\hline $\mathrm{NO}_{2}$ & $0.99(0.96-1.02)$ & $0.99(0.94-1.06)$ & $1.02(0.97-1.07)$ & $0.99(0.96-1.02)$ \\
$\mathrm{NO}$ & $1.00(0.99-1.02)$ & $1.02(0.99-1.06)$ & $1.00(0.97-1.02)$ & $1.00(0.98-1.01)$ \\
\hline $\mathrm{O}_{3}$ & $0.99(0.98-1.01)$ & $1.01(0.97-1.04)$ & $0.99(0.96-1.02)$ & $1.00(0.98-1.01)$ \\
$\mathrm{CO}$ & $1.81(0.63-5.20)$ & $0.51(0.04-6.62)$ & $0.72(0.15-3.36)$ & $0.88(0.38-2.02)$ \\
\hline Benzene & $1.19(0.90-1.56)$ & $1.03(0.54-1.97)$ & $0.99(0.66-1.47)$ & $0.95(0.77-1.17)$ \\
\hline
\end{tabular}

Adjusted for temperature, humidity, barometric pressure, day of the week, holidays, day after holidays. $\mathrm{PM}_{10}$, particles of diameter $<10$ micron; $\mathrm{SO}_{2}$ sulfur dioxide; $\mathrm{NO}_{2}$ nitrogen dioxide; $\mathrm{NO}$ nitric oxide; $\mathrm{O}_{3}$ ozone; $\mathrm{CO}$ carbon monoxide. PACl, partial anterior circulation syndrome; TACI, total anterior circulation syndrome; POCI, posterior occipital circulation syndrome; LACI, lacunar anterior circulation syndrome. * (OR 1.012; $95 \% \%$ CI 1.002-1.021), $\mathrm{P}<0.05$ 
strength of this research is the enrolment in the study of Mantua resident living within 10 $\mathrm{km}$ from the available urban air quality stations only.

This study took into account a large population that was analyzed by the technique of bidirectional case-crossover, minimizing common biases occurring in traditional case control studies and in unidirectional casecrossover designs. In fact, since each patient is his/her own control in the event-free days, confounding from time-invariant risk factors is avoided. ${ }^{33,34}$

To reduce the risk of bias due to overestimation of pollution levels many issues were carefully considered: i) the values of environmental pollutants were collected by excluding peak power units, which are those located close to major motorway networks, as they have excluded patients living within $10 \mathrm{~km}$ of major arterial roads. This was meant to limit overestimation of air pollution levels due to vehicular traffic near the monitors; ii) for the same reason, the analysis of collected data was adjusted for holidays and weekdays thereby taking into account changes in the vehicular traffic related to particular times and days of the year.

However, our study has several limitations. All patients with severe stroke who died before arriving to the hospital were not included in the study. Among these there may have been several cases of hemorrhagic stroke, which is often more severe and even fatal in a few hours. Similarly, we might have missed several TIAs and minor strokes that are a matter for the general practitioner without reaching the hospital. 35

In this study we did not evaluate the effect of $\mathrm{PM}_{2.5}$, the fraction of $\mathrm{PM}$ with a diameter less than $2.5 \mu \mathrm{m}$, which is known to better reflect the quantity of particles that are breathed deep into the lower airways and has been more consistently related with cardiovascular effects $\mathrm{PM}_{2.5}$ data on local situation became available only in 2008. ${ }^{30}$ Moreover the decreased risk of hospital admission associated to sulphur dioxide in patient with TACI is somewhat odd, contradicting previous results in animal studies and in humans; 36 anyway, the large OR confidence interval and the small number of TACI patients (57) suggest that this finding could be due to chance and need to be confirmed in another survey considering a larger number of TACI patients. Finally the magnitude of PM10 effects could be considered rather small and the statistical significance borderline, but similar issues are often evident in other similar studies ${ }^{11}$ and common when a non-categorical variable is considered in a conditional regression model with other analogous variables with no strong effect expected.

\section{Conclusions}

In this study for the first time the effect of air pollution was assessed in several stroke subtypes according TOAST and OCSP classification, suggesting a possible effect of particulate matter on lacunar strokes. Even if with some limitations, our results highlight the importance to study environmental risk factors for stroke subtypes. As a matter of facts assessing pollution effects in stroke subtypes could help to provide biological plausible explanations of pollution influence in cerebrovascular diseases, reinforcing the need of adequate measures to reduce the impact of urban air pollution on health.

\section{References}

1. Lanki T, Pekkanen J, Aalto P, et al. Associations of traffic related air pollutants with hospitalisation for first acute myocardial infarction: the HEAPSS study. Occup Environ Med 2006:63:844-51.

2. Baccarelli A, Cassano PA, Litonjua A, et al. Cardiac autonomic dysfunction: effects from particulate air pollution and protection by dietary methyl nutrients and metabolic polymorphisms. Circulation 2008; 117:1802-9.

3. Baccarelli A, Martinelli I, Pegoraro V., et al. Living near major traffic roads and risk of deep vein thrombosis. Circulation 2009; 119:3118-24.

4. Baccarelli A, Zanobetti A, Martinelli I., et al. Effects of exposure to air pollution on blood coagulation. J Thromb Haemost 2007;5:252-60.

5. Naumova EN, Yepes H, Griffiths JK, et al. Emergency room visits for respiratory conditions in children increased after Guagua Pichincha volcanic eruptions in April 2000 in Quito, Ecuador observational study: time series analysis. Environ Health 2007; $6: 21$.

6. Peters A, Döring A, Wichmann HE, Koenig W. Increased plasma viscosity during an air pollution episode: a link to mortality? Lancet 1997;349:1582-7.

7. Oudin A, Strömberg U, Jakobsson K, et al. Estimation of short-term effects of air pollution on stroke hospital admissions in Southern Sweden. Neuroepidemiology 2010;34:131-42.

8. Riediker M, Cascio WE, Griggs TR, et al. Particulate matter exposure in cars is associated with cardiovascular effects in healthy young men. Am J Respir Crit Care Med 2004;169:934-40.

9. Peters A, Perz S, Döring A, et al. Increases in heart rate during an air pollution episode. Am J Epidemiol 1999;150:1094-8.
10. Lisabeth LD, Escobar JD, Dvonch JT, et al. Ambient air pollution and risk for ischemic stroke and transient ischemic attack. Ann Neurol 2008;64:53-9.

11. Maheswaran R, Pearson T, Smeeton NC, et al. Impact of outdoor air pollution on survival after stroke: population-based cohort study. Stroke 2010;41:869-77.

12. Henrotin JB, Besancenot JP, Bejot Y, Giroud M. Short-term effects of ozone air pollution on ischaemic stroke occurrence: a case-crossover analysis from a 10-year population-based study in Dijon, France. Occup Environ Med 2007;64:439-45.

13. Bamford J, Sandercock P, Dennis M, et al. Classification and natural history of clinically identifiable subtypes of cerebral infarction. Lancet 1991;337:1521-6.

14. Adams HP Jr, Bendixen BH, Kappelle LJ, et al. Classification of subtype of acute ischemic stroke. Definitions for use in a multicenter clinical trial. TOAST. Trial of Org 10172 in acute stroke treatment. Stroke 1993;24:35-41.

15. Corea F, Silvestrelli G, Murgia N, et al. Air pollution and acute stroke hospitalization: preliminary results from Lombardia Stroke Unit Network (SUN). Cerebrovasc Dis 2009:27Suppl6:66.

16. Micieli G, Cavallini A, Quaglini S, et al. The Lombardia Stroke Unit registry: 1-year experience of a web-based hospital stroke registry. Neurol Sci 2010;31:7-12.

17. Cavallini A, Micieli G. Lombardia Stroke Unit Network Project. Neurol Sci 2006; 27Suppl3:S268-72.

18. Giacalone G, Abbas MA, Corea F. Prevention strategies for cardioembolic stroke: present and future perspectives. Open Neurol J 2010;4:56-63.

19. Paciaroni M, Silvestrelli G, Caso V, et al. Neurovascular territory involved in different etiological subtypes of ischemic stroke in the Perugia Stroke Registry. Eur J Neurol 2003;10:361-5.

20. Istat. Popolazione residente e abitazioni nelle province italiane- fascicolo provinciale Mantova. $14^{\circ}$ Censimento generale della popolazione e delle abitazioni 20012010. Available from: http://www.istat.it/dati/catalogo/20071003_00/.

21. Graff DW, Cascio WE, Rappold A, et al., Exposure to concentrated coarse air pollution particles causes mild cardiopulmonary effects in healthy young adults. Environ Health Perspect 2009;117:1089-94.

22. Maclure M. The case-crossover design: a method for studying transient effects on the risk of acute events. Am J Epidemiol 1991;133:144-53.

23. Giua A, Abbas MA, Murgia N, Corea F. Climate and stroke: a controversial association. Int J Biometeorol 2010;54:1-3. 
24. Wellenius GA, Schwartz J, Mittleman MA. Air pollution and hospital admissions for ischemic and hemorrhagic stroke among medicare beneficiaries. Stroke 2005;36: 2549-53.

25. Vidale S, Bonanomi A, Guidotti M, et al., Air pollution positively correlates with daily stroke admission and in hospital mortality: a study in the urban area of Como, Italy. Neurol Sci 2010;31:179-82.

26. Aszalos Z, Barsi P, Vitrai J, Nagy Z. Hypertension and clusters of risk factors in different stroke subtypes (an analysis of Hungarian patients via Budapest Stroke Data Bank). J Hum Hypertens 2002;16: 495-500.

27. Hajat C, Dundas R, Stewart JA, et al. Cerebrovascular risk factors and stroke subtypes: differences between ethnic groups. Stroke 2001;32:37-42.

28. Murat Sumer M, Erturk 0. Ischemic stroke subtypes: risk factors, functional outcome and recurrence. Neurol Sci 2002;22:449-54.

29. Adamopoulos D, Vyssoulis G, Karpanou E, et al. Environmental determinants of blood pressure, arterial stiffness, and central hemodynamics. J Hypertens 2010;28:903-9.

30. Brook RD, Rajagopalan S, Pope CA $3^{\text {rd }}$, et al. Particulate matter air pollution and cardiovascular disease: an update to the scientific statement from the American Heart Association. Circulation 2010;121:2331-78.

31. Masineni SN, Chander PN, Singh GD, et al. Male gender and not the severity of hypertension is associated with end-organ damage in aged stroke-prone spontaneously hypertensive rats. Am J Hypertens 2005;18:878-84.
32. Caso V, Paciaroni M, Agnelli G, et al. Gender differences in patients with acute ischemic stroke. Womens Health (Lond Engl) 2010;6:51-7.

33. Gold DR, Litonjua A, Schwartz J, et al. Ambient pollution and heart rate variability. Circulation 2000;101:1267-73.

34. Forastiere F, Stafoggia M, Berti G, et al. Particulate matter and daily mortality: a case-crossover analysis of individual effect modifiers. Epidemiology 2008;19:571-80.

35. Brotheridge S, Young J, Dowswell G, et al. A preliminary investigation of patient and carer expectations of their general practitioner in longer-term stroke care. J Eval Clin Pract 1998;4:237-41.

36. Sang N, Yun Y, Li H, et al. SO2 inhalation contributes to the development and progression of ischemic stroke in the brain. 